\title{
Delignification of Rice Husk by Microwave Assisted Chemical Pretreatment
}

\author{
S. M. Laghari \\ Civil Engineering Dpt, \\ Universiti Teknologi \\ Petronas, Malaysia \\ shuaiblaghari@ \\ gmail.com
}

\author{
M. M. Tunio \\ Energy \& Environment Dpt, \\ Quaid-e-Awam University of \\ Engineering, Science and \\ Technology, Pakistan \\ mureed.tunio@gmail.com
}

\author{
A. Q. Laghari \\ Chemical Engineering \\ Dpt, Mehran University \\ of Engineering \& \\ Technology, Pakistan \\ engrchemi@gmail.com
}

\author{
A. J. Laghari \\ Dr. M. A. Kazi \\ Institute of Chemistry, \\ University of Sindh, \\ Jamshoro, Pakistan \\ aj_balouch@ \\ yahoo.com
}

\author{
Z. M. Ali \\ Chemical Engineering \\ Dpt, Mehran University \\ of Engineering \& \\ Technology, Pakistan \\ zeenat.ali@ \\ faculty.muet.edu.pk
}

\begin{abstract}
Rice husk has the potential to be used as a source of alternative energy e.g. as biofuel. Its high lignin content, however, poses difficulty to this use. This study investigates the use of microwave assisted acidic and alkaline pretreatment methods to improve the characteristics of rice husk for energy production. The use of microwave assisted $3.5 \% \mathrm{NaOH}$ provided optimum pretreatment of rice husk; the lignin content was reduced from 17.8 to $10.2 \%$, the cellulose content increased from 38.6 to $59.3 \%$ and the $\mathrm{C} / \mathrm{N}$ ratio was within the optimum range of $25-35$. The results showed enhanced potential of biofuel production from rice husk by this pretreatment.
\end{abstract}

Keywords-chemical pretreatment; microwave; rice husk; lignocellulose biomass

\section{INTRODUCTION}

Fossil fuels have been a main energy source in modern world. Their continuously diminishing reserves, however, have raised concerns about their sustainability. Pollutants from the derivation and usage of these fuels are also detrimental to the environment. These concerns stipulate an energy source, that is economical, abundantly available, sustainable, and environment friendly [1,2]. Agricultural wastes (biomass) are viewed as good candidates for alternative energy sources. With an estimated worldwide annual production of 140 billion metric tonnes, agricultural wastes have the potential to produce energy approximately equivalent to 50 billion tonnes of oil. Biomass derived energy contributes to energy security and clean climate change mitigations, and is environment friendly and carbon neutral [3]. Producing biogas by anaerobic digestion of different solid wastes and residues, like municipal solid wastes and agricultural solid wastes, has been experimentally investigated and due to its economic feasibility, it is considered one of the best future options available $[4,5]$. Agricultural biomass waste along with holocelluloses also contains lignin. The holocelluloses are tightly packed by the lignin layers, these lignin layers limit digestion by acting as a protective wall in plant materials. Thus the lignocellulose biomass pretreatment is necessary for an effective and rapid biodegradation or anaerobic digestion. Pretreatment causes delignification and results in increased surface area and porosity of biomass, while decreasing the holocelluloses crystallinity and reducing the degree of polymerization. Pretreatments are classified as:

- Mechanical or Physical pretreatment: In this pretreatment the lignocellulose biomass waste is pretreated by different physical techniques like milling, grinding, irradiation, thermal, and hydrothermal.

- Chemical and Physico-Chemical pretreatment: in this pretreatment the lignocellulose biomass waste is mixed with chemicals, or soaked in chemical solutions, like acid, alkali, or oxidizing agents. This pretreatment also includes gas treatment, steam explosion, and solvent extraction techniques.

- Biological pretreatment: in this pretreatment the fungi and/or actinomycetes are used to pretreat the lignocellulose biomass waste biologically $[4,6]$.

All the pretreatment techniques are useful in treating lignocellulose biomass, but the effectiveness of any pretreatment varies widely and is determined by the method selected. Researchers have reported that chemical or physicochemical pretreatment provides better results in treating lignocellulose feed stocks as compared to other treatments [6].

There are several treatment techniques classified as chemical or physico-chemical pretreatment, but acidic and alkaline pretreatments are considered most effective and useful for lignocellulose disruption. Different acidic or the alkaline concentration solutions are used for pretreatment, but mostly dilute acid and alkaline concentrations are preferred so that the chemical concentration must only be sufficient to disrupt the lignin content, as high concentrations may result in the loss of holocelluloses, which is to be degraded into biofuels. Authors in [7] reported increase in cellulose content to more than $50 \%$ using 0.5 to $1 \%$ sulphuric acid pretreatment on rice straw. Authors in [8] compared various alkaline pretreatments to evaluate their effects on lignin disruption and enzymatic digestibility of various lignocellulose biomass (Eucalyptus residue, Larixleptolepis, Pinups rigida, rice straw and barley 
straw); they found that alkaline pretreatments were effective in lignin degradation. Authors in [9] studied the time reaction of alkaline pretreatment on rice husk and found that alkaline pretreatment caused lignin degradation. Microwave irradiation is also a useful physical pretreatment and has been shown to be very effective over conventional thermal treatment for waste sludge [10]. In [11] microwave assisted alkali pretreatment was used for rice straw and reported increase in cellulose content from $38.9 \%$ to $69.3 \%$ with lignin reduction from 13.6 to $5 \%$. In [12] sugarcane baggase lignocellulose disruption was studied by using microwave assisted sulphuric acid, and reported increase in cellulose content from $52.25 \%$ to $67.31 \%$. Rice husk is one of the most abundant agricultural wastes. The worldwide annual husk output is about 140 million tonnes [13]. It has good potential for bioethanol production [14], however like other lignocellulosic biomass it also contains high lignin content. Rice husk has been successfully pretreated for enhancing energy generation as a result of delignification and sachrification. Authors in [15] studied the pretreatment of rice husk with various acidic and alkaline solutions, and found that hydrochloric acid produced best results by increasing cellulose content to $65.1 \%$. Authors in [16], investigated wet air oxidation pretreatment, and found that under optimized conditions it is possible to decrease lignin from $19.4 \%$ to $4.46 \%$ and increase cellulose content from $42.2 \%$ to $65.33 \%$. Authors in [17] studied the ultrasonic pretreatment for increasing bio-oil yield, and reported that yield of bio-oil increased from $37.1 \%$ to $42.8 \%$, as a result of delignification and increased exposure of cellulose. In [18], the comparative effects of pretreatment using dilute sulphuric acid and sodium hydroxide on rice husk for bioethanol production and enzymatic hydrolysis were studied, and it was reported that $3 \%$ sodium hydroxide was successful in reducing lignin content from $19.2 \%$ to $9.6 \%$ and increasing cellulose content from $37.6 \%$ to $54.2 \%$.

\section{MATERIALS AND METHODS}

\section{A. Materials}

Rice husk was obtained locally at Tronoh, and was milled and ground to the size of $1 \mathrm{~mm}$ or less by using a Rocklabs mortar grinder type BTRM Model 1A. The ground rice husk was then subjected to the soxhlet extraction overnight by NREL extractives removal procedure $[19,20]$ to remove extractives in order to get accurate lignin values, after extractives removal the rice husk sample was placed in the air tight containers for use later.

\section{B. Chemical Solutions}

A total of 12 solutions using four chemicals viz., Sulphuric Acid, Sodium Hydroxide, Hydrogen peroxide, and Sodium carbonate, each at 3 different concentrations i.e. $2 \%, 3.5 \%$, and $5 \%$ were prepared. Strong solutions of Sodium Hydroxide and Sodium Carbonate were prepared using solid pellets, and then they were diluted to the desired strength. $1 \mathrm{~g}$ of rice husk was mixed with $10 \mathrm{ml}$ of each solution for 48 hours, the sample was then heated by microwave irradiation for $5 \mathrm{~min}$. Each experiment and analysis was at least repeated three times.

\section{Microwave}

Faber Microwave Oven Model FMO 7020 with input power $1050 \mathrm{~W}$ and output power of 700 watt was used. This Microwave oven has 5 settings as Low, Medium Low, Medium, Medium High, and High, with the output of $17 \%$, $33 \%, 55 \%, 77 \%$, and $100 \%$ microwave energy respectively [21]. In this pretreatment Medium Low setting with 33\% output microwave energy was used.

\section{Analytical methods}

The elemental analysis was performed using Leco CHN900/CHNS-932/VTF-900 elemental analyzer before and after pretreatment. Rice husk samples were analyzed for composition, to determine the quantity of cellulose, hemicellulose, and lignin content before and after pretreatment by standard procedure according to [22]. In this process lignin was analyzed by two stage acid hydrolysis and the carbohydrates were examined by HPLC. The HPLC system consisted of Agilent HiPlexpb column and refractive index (RI) detection system. The isocratic mobile phase selected was deionized water at a flow rate of $0.6 \mathrm{ml} / \mathrm{min}$ and $80^{\circ} \mathrm{C}$. and the moisture content was obtained by drying overnight in oven at $105^{\circ} \mathrm{C}$ by the procedure specified in [23], while the ash content was analyzed by using a benchtop muffle furnace in accordance with [24].

\section{RESULTS AND DISCUSSION}

\section{A. Elemental Composition}

Table I shows elemental composition with $\mathrm{C} / \mathrm{N}$ ratios obtained by different microwave assisted chemical pretreatment methods. $\mathrm{C} / \mathrm{N}$ ratio of 22.7 was observed for untreated rice husk, while the pretreated rice husks gave a range of $\mathrm{C} / \mathrm{N}$ ratios varying from 10.4 to 40.7 .

TABLE I. ELEMENTAL COMPOSITION OF RICE HUSK BEFORE AND AFTER PRETREATMENT

\begin{tabular}{|c|c|c|c|c|}
\hline Serial No. & Sample & Carbon \% & Hydrogen $\%$ & Nitrogen $\%$ \\
\hline 01 & $\begin{array}{l}\text { Untreated } \\
\text { Rice Husk }\end{array}$ & 40.60 & 5.06 & 1.79 \\
\hline \multicolumn{5}{|c|}{ NaOH MW Treated Rice Husk } \\
\hline & $2 \%$ & 32.94 & 3.84 & 0.81 \\
\hline & $3.5 \%$ & 36.72 & 3.33 & 1.20 \\
\hline & $5 \%$ & 38.81 & 4.51 & 1.39 \\
\hline \multicolumn{5}{|c|}{$\mathrm{Na}_{2} \mathrm{CO}_{3} \mathrm{MW}$ Treated Rice Husk } \\
\hline & $2 \%$ & 29.02 & 2.53 & 1.17 \\
\hline & $3.5 \%$ & 25.07 & 4.38 & 1.38 \\
\hline & $5 \%$ & 22.12 & 2.43 & 1.69 \\
\hline \multicolumn{5}{|c|}{$\mathrm{H}_{2} \mathrm{O}_{2}$ Treated Rice Husk } \\
\hline & $2 \%$ & 24.32 & 2.99 & 1.07 \\
\hline & $3.5 \%$ & 23.77 & 3.50 & 1.38 \\
\hline & $5 \%$ & 22.37 & 1.97 & 1.64 \\
\hline \multicolumn{5}{|c|}{$\mathrm{H}_{2} \mathrm{SO}_{4} \mathrm{MW}$ Treated Rice Husk } \\
\hline & $2 \%$ & 21.30 & 1.97 & 0.95 \\
\hline & $3.5 \%$ & 18.13 & 1.85 & 1.27 \\
\hline & $5 \%$ & 14.69 & 1.59 & 1.41 \\
\hline
\end{tabular}

The minimum and maximum $\mathrm{C} / \mathrm{N}$ ratios were obtained for pretreatments with $5 \%$ sulphuric acid and $2 \%$ sodium hydroxide respectively. $\mathrm{C} / \mathrm{N}$ ratio range of 25 to 35 is considered suitable for optimum biogas production by 
anaerobic digestion [25]. It was observed that the pretreatments by $3.5 \%$ sodium hydroxide, and $5 \%$ sodium hydroxide, increased the $\mathrm{C} / \mathrm{N}$ ratio of rice husk to the optimum level as shown in Figure 1.

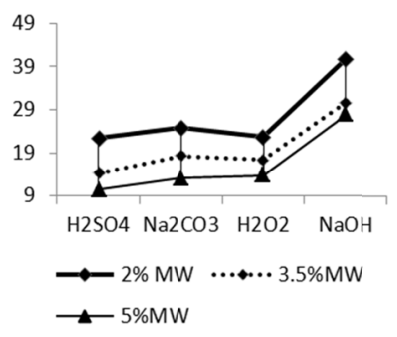

Fig. 1. $\quad \mathrm{C} / \mathrm{N}$ ratio of samples

\section{B. Chemical Composition}

Table II shows the composition of rice husk based on cellulose, hemicellulose, lignin, ash and moisture content. The lignin data shows that all microwave assisted chemical pretreatments applied were able to reduce the lignin content of rice husk. Figure 2 shows the percentage decrease of lignin content of microwave assisted pretreated rice husk samples. Sodium hydroxide pretreatment was found to be the most effective amongst the pretreatment methods studied. For microwave assisted alkali pretreatment using 2, 3.5, and 5\% sodium hydroxide, the percentage decrease in lignin level in the rice husk was obtained as $36.5,42.7$ and $30.3 \%$ respectively. Table II shows that cellulose content increment was observed in all microwave assisted chemical pretreatment of rice husk.
Figure 3 shows the percentage increase of cellulose content of microwave assisted pretreated rice husk samples, a significant percentage increase in cellulose content was observed in 3.5\% sodium hydroxide pretreated rice husk $(53.6 \%)$, followed by $5 \%$ sodium hydroxide $(48.7 \%), 3.5 \%$ sulphuric acid $(40.4 \%)$ and $2 \%$ sodium hydroxide $(33.7 \%)$.

\section{Energy Potential}

Cellulose has a very high potential of energy recovery, and has been successfully used for biofuel generation in the form of ethanol or biogas. It has been reported that 100 grams of cellulose can produce up to 51.4 grams of ethanol and 48.6 grams of $\mathrm{CO} 2$ [26]. It has also been reported that theoretically $710 \mathrm{ml}$ of biogas can be recovered from each gram of cellulose, with 51 to $56 \%$ methane [27]. Thus, the pretreatment performed in this study is capable of enhancing energy recovery from rice husk by increasing the cellulose content.
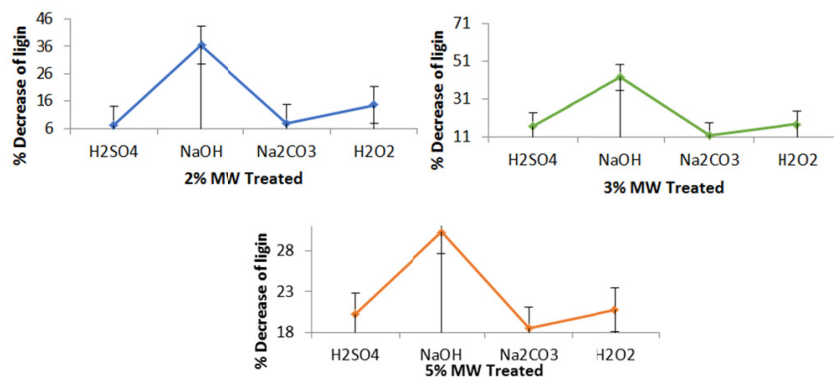

Fig. 2. Percentage decrease of lignin content in pretreated rice husk. The vertical lines shows the standard errors

TABLE II. CHEMICAL COMPOSITION OF RICE HUSK BEFORE AND AFTER PRETREATMENT

\begin{tabular}{|c|c|c|c|c|c|c|}
\hline S. No. & Sample & Cellulose $\%$ & Hemicellulose \% & Lignin \% & Ash content $\%$ & Moisture \% \\
\hline 1 & Untreated Rice Husk & 38.6 & 19.7 & 17.8 & 12.5 & 7.9 \\
\hline \multicolumn{7}{|c|}{$\mathrm{NaOH}$ MW Treated } \\
\hline & $2 \%$ & 51.6 & 13.7 & 11.3 & 13.6 & 6.3 \\
\hline & $3.5 \%$ & 59.3 & 10.5 & 10.2 & 9.4 & 6.9 \\
\hline & $5 \%$ & 57.4 & 9.3 & 12.4 & 11.2 & 6.4 \\
\hline \multicolumn{7}{|c|}{$\mathrm{Na}_{2} \mathrm{CO}_{3} \mathrm{MW}$ Treated } \\
\hline & $2 \%$ & 40.3 & 18.9 & 16.4 & 14.9 & 6.1 \\
\hline & $3.5 \%$ & 42.6 & 18.4 & 15.7 & 13.3 & 6.7 \\
\hline & $5 \%$ & 44.5 & 17.6 & 14.5 & 13.7 & 6.2 \\
\hline \multicolumn{7}{|c|}{$\mathrm{H}_{2} \mathrm{O}_{2} \mathrm{MW}$ Treated } \\
\hline & $2 \%$ & 44.3 & 17.8 & 15.2 & 12.8 & 7.2 \\
\hline & $3.5 \%$ & 47.2 & 16.1 & 14.6 & 11.2 & 7.4 \\
\hline & $5 \%$ & 48.3 & 13.6 & 14.1 & 13.3 & 7.2 \\
\hline \multicolumn{7}{|c|}{$\mathrm{H}_{2} \mathrm{SO}_{4} \mathrm{MW}$ Treated } \\
\hline & $2 \%$ & 44.7 & 15.9 & 16.5 & 12.9 & 6.5 \\
\hline & $3.5 \%$ & 54.2 & 11.4 & 14.8 & 10.3 & 6.4 \\
\hline & $5 \%$ & 49.3 & 13.8 & 14.2 & 12.8 & 6.2 \\
\hline
\end{tabular}

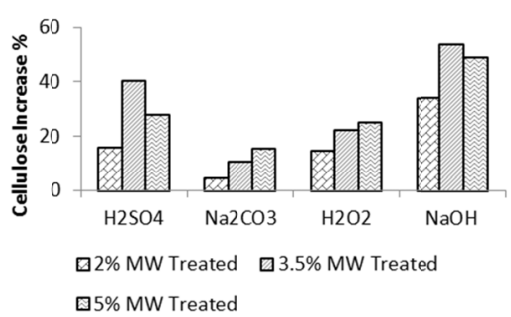

Fig. 3. Percentage of cellulose increased in pretreated rice husk

\section{CONCLUSION}

The use of rice husk as a source of alternative energy is limited by its high lignin content. The microwave assisted acidic and alkaline pretreatment methods applied in this study were able to enhance the potential of energy recovery from rice husk. The study has shown that the pretreatments performed were effective in changing the chemical composition and behavior of the rice husk samples. Optimum results were achieved with microwave assisted alkaline pretreatment using 
$3.5 \% \mathrm{NaOH}$ solution. The lignin content was reduced from 17.8 to $10.2 \%$, whereas the cellulose content increased from 38.6 to $59.3 \%$; the $\mathrm{C} / \mathrm{N}$ ratio was within the optimum range of 25-35. The increase in cellulose content will be effective in enhancing production of biofuels like bioethanol, biomethane or biohydrogen by fermentation or anaerobic digestion.

\section{ACKNOWLEDGEMENT}

Financial assistance in the form of Graduate Assistantship to the first author by the Universiti Teknologi Petrona, Seri Iskandar, Perak, Malaysia is acknowledged. The authors are thankful to the Institute of Advanced Research Studies in Chemical Sciences (IARSCS), University of Sindh, and Jamshoro, Pakistan for the assistance in sample analyses.

\section{REFERENCES}

[1] M. Fatih Demirbas, M. Balat, H. Balat, "Biowastes-to-biofuels", Energy Conversion and Management, Vol. 52, No. 4, pp. 1815-1828, 2011

[2] C. Escamilla-Alvarado, E. Ríos-Leal, M. T. Ponce-Noyola, H. M. Poggi-Varaldo, "Gas biofuels from solid substrate hydrogenogenicmethanogenic fermentation of the organic fraction of municipal solid waste", Process Biochemistry, Vol. 47, No. 11, pp. 1572-1587, 2012

[3] UNEP, Converting Waste Agricultural Biomass into a Resource, United Nations Environmental Programme, Osaka/Shiga, Japan, 2009

[4] R. Chandra, H. Takeuchi, T. Hasegawa, "Methane production from lignocellulosic agricultural crop wastes: A review in context to second generation of biofuel production", Renewable and Sustainable Energy Reviews, Vol. 16, No. 3, pp. 1462-1476, 2012

[5] K. Starr, G. Villalba, X. Gabarrell, "Upgraded biogas from municipal solid waste for natural gas substitution and $\mathrm{CO} 2$ reduction-A case study of Austria, Italy, and Spain", Waste Management, Vol. 38, pp. 105-116, 2015

[6] A. T. W. M. Hendriks, G. Zeeman, "Pretreatments to enhance the digestibility of lignocellulosic biomass", Bioresource Technology, Vol. 100, No. 1, pp. 10-18, 2009

[7] T. -C. Hsu, G. -L. Guo, W. -H. Chen, W. -S. Hwang, "Effect of dilute acid pretreatment of rice straw on structural properties and enzymatic hydrolysis", Bioresource Technology, Vol. 101, pp. 4907-4913, 2010

[8] Y. C. Park, J. S. Kim, "Comparison of various alkaline pretreatment methods of lignocellulosic biomass", Energy, Vol. 47, pp. 31-35, 2012

[9] L. S. Monte, V. A. Escócio, A. M. F. de Sousa,C. R. G. Furtado, M. C. A. M. Leite, L. L. Y. Visconte, E. B. A. V. Pacheco, "Study of time reaction on alkaline pretreatment applied to rice husk on biomass component extraction", Biomass Conversion and Biorefinery, Vol. 8, No. 189,2018

[10] C. J. Chang, V. K. Tyagi, S. -L. Lo, "Effects of microwave and alkali induced pretreatment on sludge solubilization and subsequent aerobic digestion”, Bioresource Technology, Vol. 102, pp. 7633-7640, 2011

[11] S. Zhu, Y. Wu, Z. Yu, J. Liao, Y. Zhang, "Pretreatment by microwave/alkali of rice straw and its enzymic hydrolysis", Process Biochemistry, Vol. 40, pp. 3082-3086, 2005

[12] W. H. Chen, Y. -J. Tu, H. -K. Sheen, "Disruption of sugarcane bagasse lignocellulosic structure by means of dilute sulfuric acid pretreatment with microwave-assisted heating", Applied Energy, Vol. 88, pp. 27262734, 2011

[13] Y. Chen, Y. Zhu, Z. Wang, Y. Li, L. Wang, L. Ding, X. Gao, Y. Ma, Y. Guo, "Application studies of activated carbon derived from rice husks produced by chemical-thermal process--a review", Advances in Colloid and Interface Science, Vol. 163, No. 1, pp. 39-52, 2011

[14] A. Abbas, S. Ansumali, "Global potential of rice husk as a renewable feedstock for ethanol biofuel production", BioEnergy Research, Vol. 3, pp. 328-334, 2010

[15] T. N. Ang, G. C. Ngoh, A. S. M. Chua, "Comparative study of various pretreatment reagents on rice husk and structural changes assessment of the optimized pretreated rice husk", Bioresource Technology, Vol. 135, pp. 116-119, 2013

[16] S. Banerjee, R. Sen, R. Pandey, T. Chakrabarti, D. Satpute, B. S. Giri, S. Mudliar, "Evaluation of wet air oxidation as a pretreatment strategy for bioethanol production from rice husk and process optimization", Biomass Bioenergy, Vol. 33, pp. 1680-1686, 2009

[17] W. Shi, J. Jia, Y. Gao, Y. Zhao, "Influence of ultrasonic pretreatment on the yield of bio-oil prepared by thermo-chemical conversion of rice husk in hot-compressed water", Bioresource Technology, Vol. 146, pp. 355362,2013

[18] M. Nikzad, K. Movagharnejad, G. D. Najafpour, F. Talebnia, "Comparative studies on effect of pretreatment of rice husk for enzymatic digestibility and bioethanol production", International Journal of Engineering, Vol. 26, pp. 455-464, 2013

[19] R. R. Sluiter, C. Scarlata, J. Sluiter, D. Templeton, Determination of Extractives in Biomass. National Renewable Energy Laboratory, 2005

[20] M. P. da Rosa, P. H. Beck, D. G. Müller, J. B. Moreira, J. S. da Silva, A. M. M. Durigon, "Extraction of organosolv lignin from rice husk under reflux conditions", Biological and Chemical Research, pp. 87-98, 2017.

[21] Faber, FABER Microwave Oven Instruction Manual, Model: FMO 7020

[22] A. Sluiter, B. Hames, R. Ruiz, C. Scarlata, J. Sluiter, D. Templeton, D. Crocker, Determination of structural carbohydrates and lignin in biomass, National Renewable Energy Laboratory, U. S. Department of Energy, 2012

[23] A. Sluiter, B. Hames, D. Hyman, C. Payne, R. Ruiz, C. Scarlata, J. Sluiter, D. Templeton, J. Wolfe, Determination of total solids in biomass and total dissolved solids in liquid process samples, National Renewable Energy Laboratory, U. S. Department of Energy, 2008

[24] A. Sluiter, B. Hames, R. Ruiz, C. Scarlata, J. Sluiter, D. Templeton, Determination of ash in biomass laboratory analytical procedure (LAP), National Renewable Energy Laboratory, U. S. Department of Energy, 2008

[25] W. Mussoline, G. Esposito, A. Giordano, P. Lens, "The anaerobic digestion of rice straw: a review", Critical Reviews in Environmental Science and Technology, Vol. 43, No. 9, pp. 895-915, 2013

[26] P. C. Badger, "Ethanol from cellulose: a general review" in: Trends in New Crops and New Uses, ASHS Press, Alexandria, 2002

[27] A. W. Khan, T. M. Trottier, G. B. Patel, S. M. Martin, "Nutrient requirement for the degradation of cellulose to methane by a mixed population of anaerobes", Journal of General Microbiology, Vol. 112, pp. 365-372, 1979 